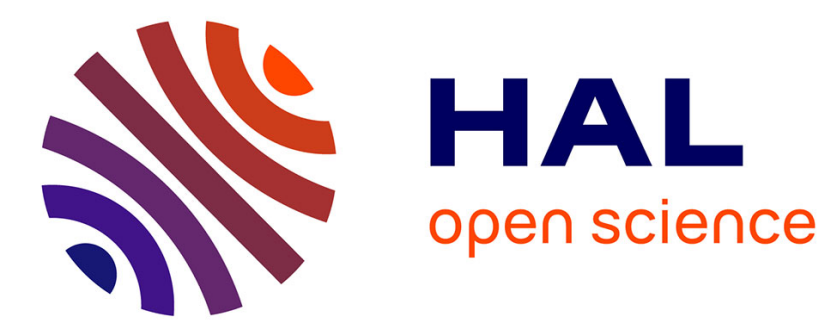

\title{
An experimental study of square tube crushing under impact loading using a modified large scale SHPB
}

Han Zhao, Salim Abdennadher, Ramzi Othman

\section{To cite this version:}

Han Zhao, Salim Abdennadher, Ramzi Othman. An experimental study of square tube crushing under impact loading using a modified large scale SHPB. International Journal of Impact Engineering, 2006, 32 (7), pp.1174-1189. 10.1016/j.ijimpeng.2004.09.013 . hal-01006852

\section{HAL Id: hal-01006852 \\ https://hal.science/hal-01006852}

Submitted on 31 Oct 2018

HAL is a multi-disciplinary open access archive for the deposit and dissemination of scientific research documents, whether they are published or not. The documents may come from teaching and research institutions in France or abroad, or from public or private research centers.
L'archive ouverte pluridisciplinaire HAL, est destinée au dépôt et à la diffusion de documents scientifiques de niveau recherche, publiés ou non, émanant des établissements d'enseignement et de recherche français ou étrangers, des laboratoires publics ou privés. 


\title{
An experimental study of square tube crushing under impact loading using a modified large scale SHPB
}

\author{
Han Zhao ${ }^{\mathrm{a}, *}$, Salim Abdennadher ${ }^{\mathrm{a}}$, Ramzi Othman ${ }^{\mathrm{b}}$ \\ ${ }^{a}$ Laboratoire de Mécanique et Technologie-Cachan, ENS-Cachan/Université Pierre \& Marie Curie/CNRS, 61, \\ Avenue du président Wilson, 94235 Cachan cedex, France \\ ${ }^{\mathrm{b}}$ Laboratoire de Mécanique des Solides, Ecole Polytechnique, 91128 Palaiseau cedex, France
}

This paper presents an experimental study on square tubes made from a rate insensitive material under static and impact loading. Rate insensitivity of the base material $(\mathrm{Cu}-\mathrm{Zn}$ alloy) is confirmed by static and dynamic tests on small samples cut from the tubes. A direct impact large scale Hopkinson bar $(80 \mathrm{~mm}$ diameter, $10 \mathrm{~m}$ length) system is used to perform tube crushing tests. A two-point measurement method is applied to extend measuring duration of the pressure bar, which is usually limited by its length. The proposed method permits to monitor the whole tube crushing process.

Static and impact tests $(7-15 \mathrm{~m} / \mathrm{s})$ on these square tubes reveal that there is a significant increase under impact loading of both initial and successive peak loads with respect to quasi-static loading. Such a study is useful for the understanding of strength enhancement under impact loading observed for cellular materials such as honeycombs.

Keywords: Dynamic buckling; Brass tube; Honeycomb; Kolsky’s bar; Impact; Wave separation

*Corresponding author. Tel.: +33147402039; fax: + 33147402240 .

E-mail address: zhao@lmt.ens-cachan.fr (H. Zhao). 


\section{Introduction}

Significant strength enhancement under impact loading were observed for cellular materials such as aluminium honeycombs [1-4]. It is also observed that the proportion of such enhancement is much stronger than the rate sensitivity of base material, from which corresponding cellular structures are made. This observation suggests the existence of other structural reasons for this surplus enhancement, for instance, the inertia effect reported by Calladine and English [5].

To understand the cause responsible for this surplus enhancement, one of the simple methods is to study a hollow box column made form totally rate insensitive metals. Such a model structure is found with commercially available brass square tubes (after suitable partial annealing). In this paper, an experimental study of such annealed brass square tube is presented. Section 2 reported annealing and quenching process, which is necessary to obtain a repeatable base material characteristics and a suitable progressive crushing mode. Tests on the brass tube under quasistatic loading are also presented. In Section 3, the base material behaviour under static and dynamic loading (up to $2500 / \mathrm{s}$ ) is characterised in order to ensure its rate insensitivity in this range of strain rates. Dynamic experimental results of tube crushing is presented in Section 4, using a modified large scale (10 $\mathrm{m}$ long and $80 \mathrm{~mm}$ diameter) split Hopkinson pressure bar system. The classical SHPB measuring duration is not long enough to work at large displacements, necessary for tube crushing. Therefore, a two-gauge measurement wave separation method is used to allow for a long test duration. Significant increase of crushing strength is observed for studied square tubes made from the rate insensitive brass.

\section{Quasi-static test of brass square tube}

Thirty five millimetres $\times 35 \mathrm{~mm}$ commercial brass square tubes of $1.5 \mathrm{~mm}$ wall thickness were chosen because of the restrictions of the testing device (Cross-section size and maximum load). However, strain hardening produced during manufacturing made the as-received tubes brittle so that the successive crushing mode as honeycombs was not observed because of early fractures at the four edges (Fig. 1, on the left). Annealing was therefore necessary in order to make the tubes more ductile.

The main aim of this annealing is to increase the ductility. However, one should obtain a homogeneous and stable material property everywhere in the tube after annealing and the process should be repeatable. The exact chemical composition of the brass tubes $(\mathrm{Cu} 64 \%, \mathrm{Zn} 36 \%)$ were measured using an EDS microprobe (Fig. 2). The corresponding phase equilibrium diagram indicates the temperature range needed. Different annealing programs (temperature and time) have been tested. The final program is described as following: $30 \mathrm{~min}$ annealing at $450{ }^{\circ} \mathrm{C}$ and water quenching in order to fix the microstructure.

This heat treatment guaranties a good reproducibility of material properties. Indeed, static crushing tests were performed on treated tubes with a MTS810 universal testing machine. In order to avoid global elastic buckling mode, the length of the tube specimen is chosen to be $104 \mathrm{~mm}$.successive folding mode is observed (Fig. 1, on the right) and force-displacement recordings are repeatable (Fig. 3). It indicates that the applied heat-treatment is repeatable and quite homogeneous because the buckling mode is generally sensitive to the local weak points. 


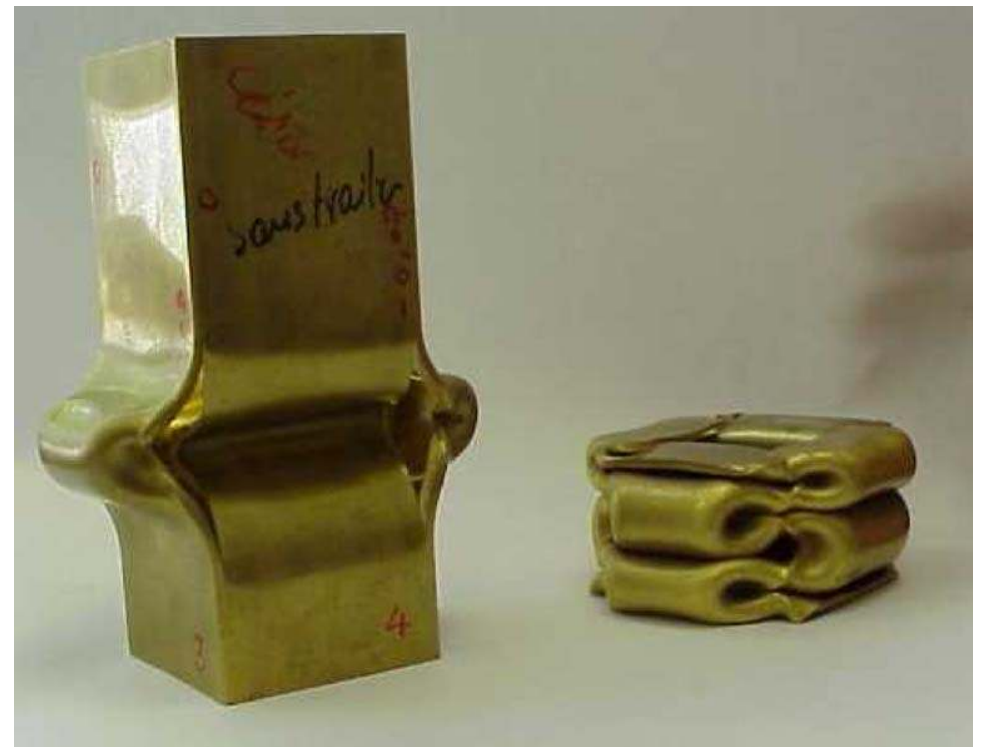

Fig. 1. Crushing mode of brass tube before (on the left) and after (on the right) heat treatment.

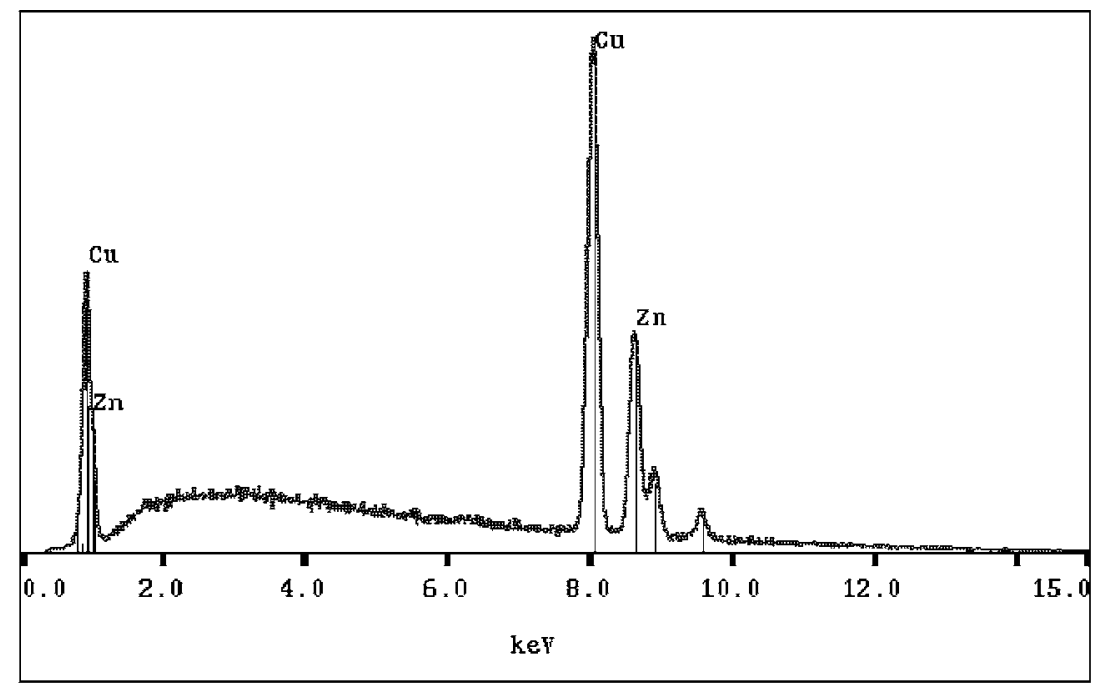

Fig. 2. EDS microanalysis of brass tubes.

\section{Experimental rate sensitivity characterisation of base materials}

In order to ensure that the basic material is rate insensitive, especially after annealing, tests under a comparable loading mode (static as well as dynamic) were performed to determine if the partially annealed base material (brass) is rate insensitive. Compressive tests were chosen for the following reasons: (i) the main loading mode in tube crushing is compression; (ii) under dynamic 


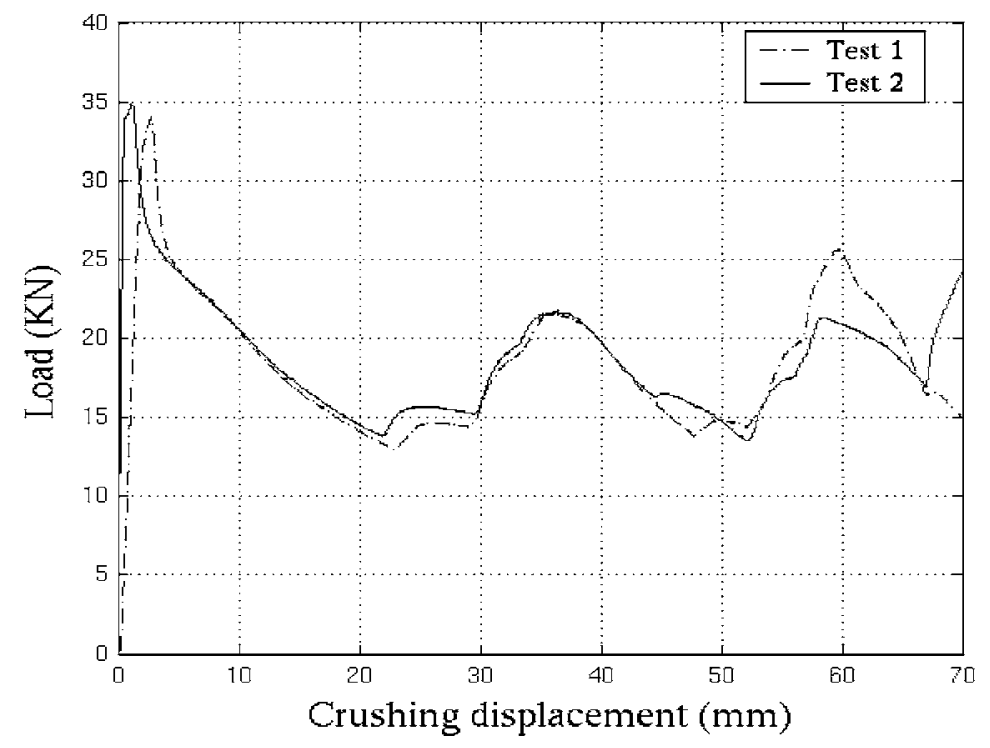

Fig. 3. Reproducible static crushing tests of annealed brass tubes.

loading, compression with a split Hopkinson pressure bar (SHPB) is much more accurate than tension because of the specimen shape and attachment difficulties.

Specimens were cut from heat treated brass tubes. Their dimensions were about $1.5 \mathrm{~mm}$ thick, $2 \mathrm{~mm}$ high and $10 \mathrm{~mm}$ wide (see also Fig. 4a).

\subsection{Quasi-static tests with optical measurement of strain field}

Such specimens were tested with an MTS 810 universal testing machine at $0.001 \mathrm{~mm} / \mathrm{s}$. The force was measured by the load cell of the machine. As the specimen height was small $(2 \mathrm{~mm})$, it is hard to attach a strain gauge to the specimen. The displacement measurement of the machine is believed not to be accurate enough to obtain a reliable strain measurement, even if the stiffness of the test machine is known and corrected for (subtraction of the deformation of the machine frame under loading). In addition, we need to verify that the strain field is a homogenous compressive one.

An alternative is to use an optical displacement field measurement. The principle is to compare images of the specimen taken during the test by means of a Kodak Megaplus CCD camera and a long-distance microscope Questar QM100. An image processing technique based on crosscorrelation allows matching of the same material points in different images, thus giving their displacements. The software developed at our laboratory (Laboratoire de Mécanique et Technologie) was used to perform this image processing task. It can give sub-pixel accuracy for displacement and a precision in the strain of at least $10^{-4}$ with an 8-bit $1008 \times 1016$ pixel optical camera [6]. Such optical measurement of the strain field provides a check on the effect of friction as well as the parallelism of the two faces. It proved that the test produces a uniform compression. Fig. 4a presents schematically the position of camera image area within samples. Fig. 4b shows a series of images taken during the test. 


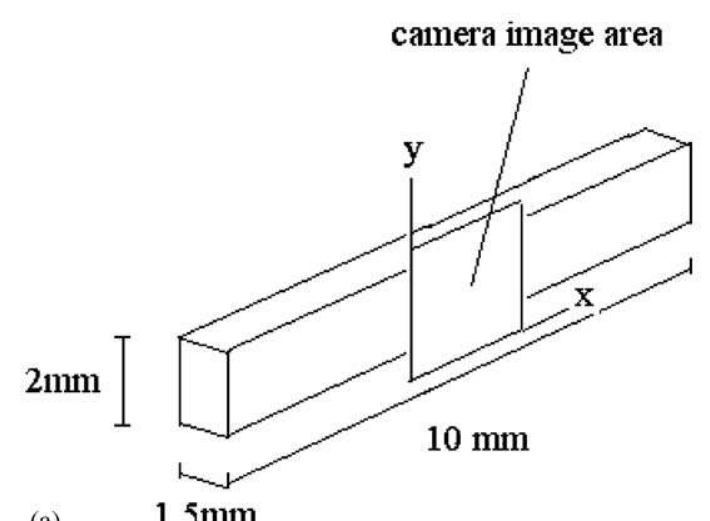

(a)
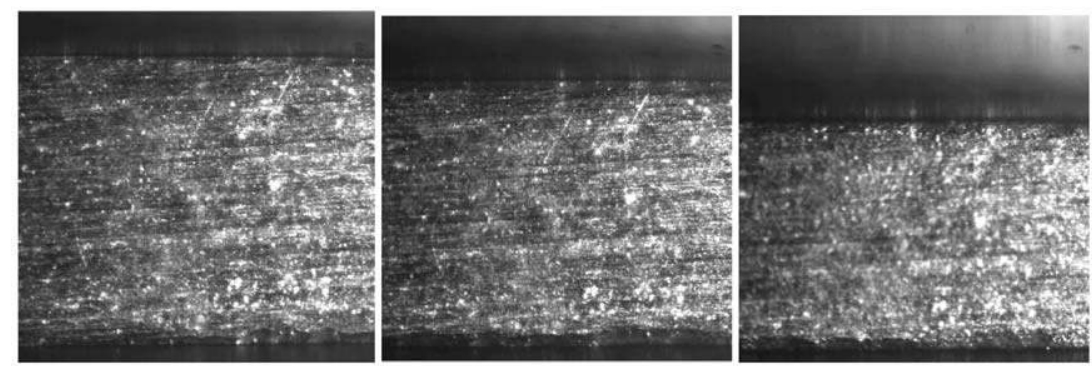

(b)

Fig. 4. (a) Camera image area and compression samples. (b) Three images corresponding to different compressive stages.
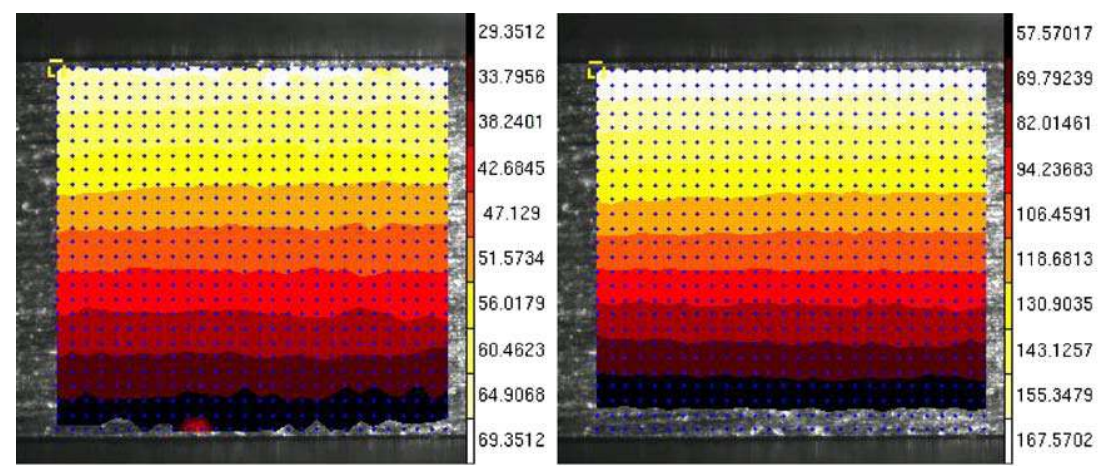

Fig. 5. Corresponding displacement in $y$-direction.

Displacement fields can be calculated between two successive images. Fig. 5 illustrates the calculated displacement fields (expressed as pixels) in vertical $y$-direction (loading direction) for the 2 nd and 3rd images, taking 1st image as a reference. Fig. 6 shows the calculated horizontal $x$ direction normal strain (6a), shear (6b) and vertical $y$-direction normal strain map (6c) between 


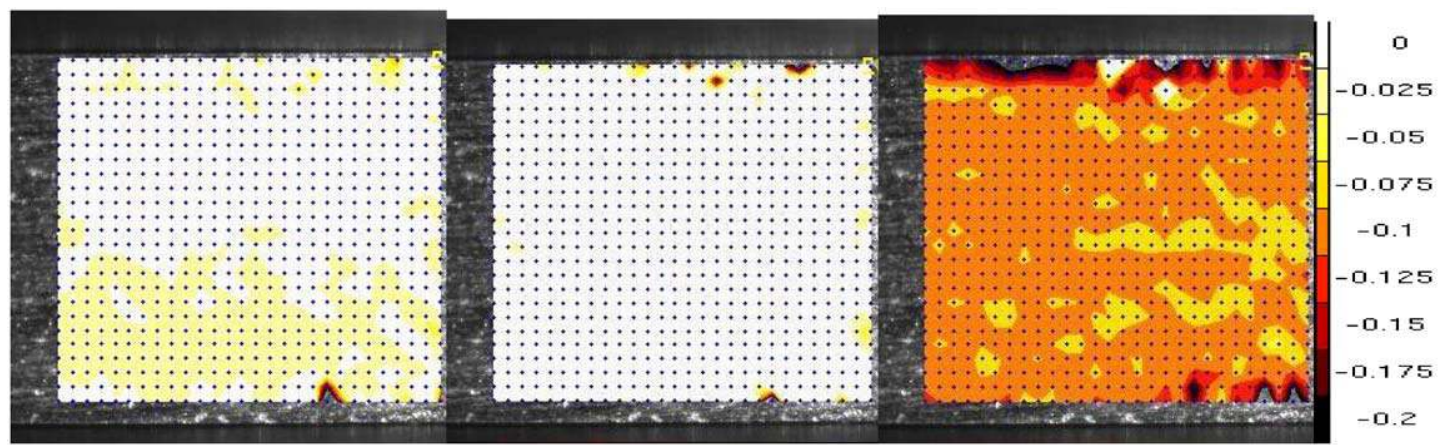

(a)

(b)

(c)

Fig. 6. Calculated strain fields (a) $x$-direction normal strain (b) shear (c) $y$-direction normal strain.

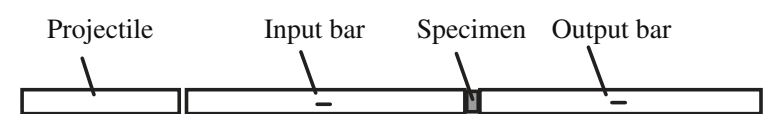

Fig. 7. SHPB setup.

1st and 2nd images, respectively. The calculated strain map illustrate clearly that the test is a good quality compression one.

\subsection{Dynamic test using SHPB}

Dynamic tests were performed with SHPB or Kolsky's apparatus which has become today a very popular experimental technique for the study of the constitutive laws of the materials at high strain rates $[7,8]$.

A typical SHPB set-up is outlined in Fig. 7. It is composed of long input and output bars with a short specimen sandwiched between them. Impact of the projectile at the free end of input bar develops a compressive longitudinal incident wave $\varepsilon_{\mathrm{i}}(t)$. Once this wave reaches the bar specimen interface, a part of it, $\varepsilon_{\mathrm{r}}(t)$, is reflected, whereas a second part is transmitted through the specimen to the output bar (the transmitted wave $\varepsilon_{t}(t)$ ).

Those three basic waves recorded by two gauges cemented on the input and output bars permit to calculate forces and velocities at the two faces of the specimen.

$$
\begin{array}{ll}
F_{\text {input }}(t)=S_{\mathrm{B}} E\left(\varepsilon_{\mathrm{i}}(t)+\varepsilon_{\mathrm{r}}(t)\right), & V_{\text {input }}(t)=C_{0}\left(\varepsilon_{\mathrm{i}}(t)-\varepsilon_{\mathrm{r}}(t)\right), \\
F_{\text {output }}(t)=S_{\mathrm{B}} E \varepsilon_{\mathrm{t}}(t), & V_{\text {output }}(t)=C_{0} \varepsilon_{\mathrm{t}}(t),
\end{array}
$$

where $S_{\mathrm{B}}, E$ and $C_{0}$ are the bar's cross-sectional area, Young's modulus, and the elastic wave speed, respectively.

One problem in the use of the SHPB is the shifting of elastic waves measured at the midpoints of the bars to the bar-specimen interfaces where the forces and velocities are needed. Careful data processing is necessary to obtain this shift [9-11], which was performed with the special program DAVID written at the Laboratoire de Mécanique des Solides. 
Afterwards, the classical analysis which assumes the axial uniformity of stress and strain fields in the specimen can be applied. An average stress-strain curve can be obtained (like those obtained from a quasi-static test) which lead to the so-called two-wave analysis

$$
\begin{aligned}
\dot{\varepsilon}_{\mathrm{s}}(t) & =\frac{V_{\text {output }}(t)-V_{\text {input }}(t)}{l_{\mathrm{e}}}, \\
\sigma_{\mathrm{s}}(t) & =\frac{F_{\text {output }}(t)}{S_{\mathrm{e}}},
\end{aligned}
$$

where $l_{\mathrm{e}}, S_{\mathrm{e}}$ are the length and cross-sectional area of samples.

Such homogeneous assumption is not really correct under dynamic loading, at least at the early stage of the test because of the transient effects: the loading starts at one face of the specimen whereas the other face remains at rest. A three-waves analysis has been then proposed to use the average of the two forces to calculate the stress (Eq. (2c)) instead of Eq. (2b) [12]

$$
\sigma_{\mathrm{s}}(t)=\frac{F_{\text {input }}(t)+F_{\text {output }}(t)}{2 S_{\mathrm{e}}} .
$$

For our test, a steel SHPB of $20 \mathrm{~mm}$ diameter was used. The specimen placed between bars was lubricated to reduce friction. Signals were sampled at $1 \mathrm{MHz}$ using an integrated data acquisition card. The experimental results were reproducible with nearly no scatter.

Fig. 8 shows the comparison of strain-stress relations of annealed brass at quasi static rate and various strain rate up to $2500 / \mathrm{s}$. The stress-strain curves under dynamic loading is obtained with three-wave method (Eq. (2c)). Curves under quasi-static loading is calculated from the force measured by a load cell and the displacement measured by displacement measurement of the

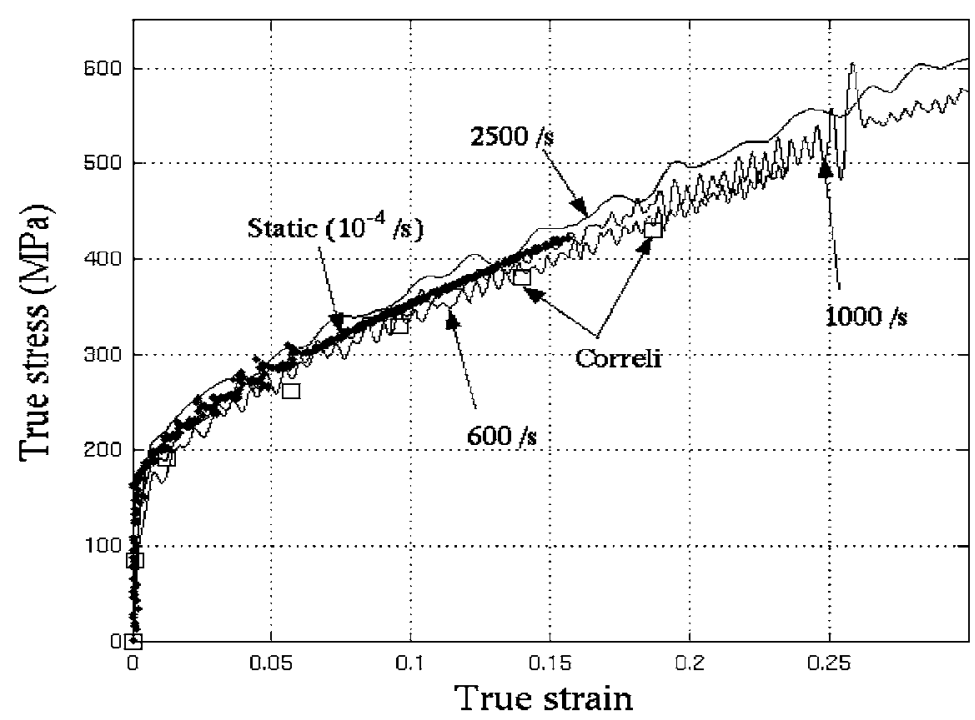

Fig. 8. Stress-strain relations at static and dynamic strain rates. 
testing machine and corrected with testing machine stiffness. The small square is the Correli images measurement. It is clear that there is no significant rate sensitivity.

\section{Dynamic crushing test of brass tubes}

\subsection{The large scale direct impact Hopkinson bar test}

Steel or aluminium square tubes have been extensively studied during last decades [13-15]. However, most of the testing results reported in the literature are obtained with falling weight device, probably because of the energy needed in the crushing and large size of the tube. In such tests, the deceleration of the falling mass is measured by an accelerometer. Associated force and displacement are deduced afterwards. The measuring accuracy can be poor because of the vibrations of the weight and its suspension system. Thus, previous works in open literature sometimes report only the final crushing displacement at a given impacting mass and velocity.

As we aimed at comparing accurately quasi-static and dynamic force-crushing displacement curves, an accurate force and displacement measurement during the test is highly desired. A new testing configuration should be then developed. The use of Hopkinson pressure bar technique is naturally motivated because of its measuring accuracy. Other standard testing machines do not take thoroughly into account the wave propagation phenomenon and consequently do not offer accurate measurements at high strain rate [16].

In this paper, the use of Hopkinson pressure bar is proposed. However, the application of SHPB to tubes requires a large diameter bar to cover the tube section. A large scale SHPB system (bars' diameter $80 \mathrm{~mm}$, input bar of $6 \mathrm{~m}$ and output bar $4 \mathrm{~m}$ ) is then used. Meanwhile, another problem raises: the energy of incident pulse is not sufficient to crush brass tubes up to a large crushing distance at a quite stable velocity. In the classical arrangement of SHPB, the loading pulse is limited by the length of the projectile. A simple modification was therefore made. It consists to put specimen at the front of the input bar [17]. The projectile of $2 \mathrm{~m}$ length and $80 \mathrm{~mm}$ diameter (about $100 \mathrm{~kg}$ ) impacts directly the brass tube (Fig. 9). The energy necessary is then guaranteed. The two bars are put in contact as to make just one bar with two strain gauges as shown in Fig. 9. Such a testing configuration gives another advantage : the bar's length is now $10 \mathrm{~m}$.

\subsection{Extension of measuring duration}

Unfortunately, even with this long bar, the measuring duration of SHPB is not yet sufficient. Indeed, the measuring technique using bars relies on the knowledge of the two elementary waves

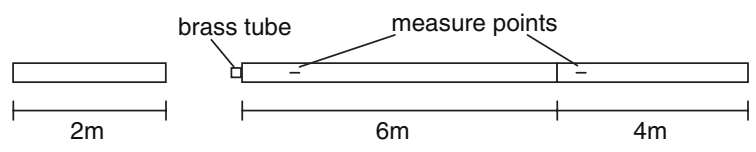

Fig. 9. A modified SHPB setup, block bar. 
propagating in opposite directions. The SHPB technique uses long bars and a short loading pulse so that there exists a cross-section where the total incident pulse and the corresponding reflected waves can be recorded separately. There exists then a maximum observation duration depending on the length of the bar and the measuring duration $\Delta T$ of a classical SHPB set-up, which is approximately limited [8] to $\Delta T L / C, C$ being wave speed and $L$ the length of the bar. Consequently, the total relative displacement $\Delta L$ between the two bar-specimen interfaces is limited for a given loading speed $V(\Delta L V \Delta T)$. The measurable duration does not exceed $4 \mathrm{~ms}$ for a SHPB set-up made of $10 \mathrm{~m}$ long steel bars $(C \cong 5000 \mathrm{~m} / \mathrm{s})$ and the measurable maximum displacement is limited then to $40 \mathrm{~mm}$ for an impact velocity of $10 \mathrm{~m} / \mathrm{s}$.

This large scale SHPB fails in our case to record the second peak load (progressive folding peak load) which appears after $40 \mathrm{~mm}$ crushing displacement (see Fig. 3). In order to increase the measuring duration, a two-point measurement method has to be used to separate two waves propagating in opposite directions in the bars.

Some earlier workers have already analysed the multiple reflections in bars. Campbell and Duby [18] have reported a method on the basis of one-dimensional elastic wave theory. Lundberg and Henchoz [19] have also proposed a simple explicit formula (within one-dimensional wave propagation assumption) to separate the two elementary waves and to measure the particle velocity after an observation window, using two signals recorded at two different cross-sections in a bar. Zhao and Gary $[10,20]$ have extended such a method to take into account wave dispersion effect using an iterative scheme. Meng and Li [21] used the same scheme with close strain gauges that are near from the bar end. These methods use two strain measurement on each bar. Park and Zhou [22] applied the iterative scheme of Zhao and Gary [10,20] to the case of one strain measurement and one end condition on each bar. Casem et al. [23] proposed a method using one strain and one velocity measurement in the same position on each bar. To reduce noise effect, Othman et al. [24], Bussac et al. [25] and Jacquelin and Hamelin [26] proposed multi-point measurements.

Considering the two elementary waves in a bar, the wave propagating in the positive direction (arbitrarily defined) is named the "ascending" wave and the other one the "descending" wave (to avoid the confusion with the classical SHPB, the terms "incident wave" and "reflected wave" are not used here). The strain $\varepsilon(t)$ at each section is the sum of the contribution of the elementary "ascending" wave $\varepsilon_{\text {asc }}(t)$ and that of the elementary "descending" wave $\varepsilon_{\text {des }}(t)$, and the velocity $v(t)$ is proportional to their difference

$$
\begin{aligned}
& \varepsilon(t)=\varepsilon_{\mathrm{asc}}(t)+\varepsilon_{\mathrm{des}}(t), \\
& v(t)=C_{0}\left(\varepsilon_{\mathrm{asc}}(t)-\varepsilon_{\mathrm{des}}(t)\right),
\end{aligned}
$$

where $C_{0}$ is the wave speed.

We note that here the bar is $80 \mathrm{~mm}$ in diameter. The geometry dispersive effects are important and the dispersion correction should be applied. The analytical solution of the propagation of longitudinal waves in an infinite elastic bar obtained by Pochhammer [27] and Chree [28] can be used to describe wave propagations as many other workers $[9,11,29]$. Such an approach relies on the assumption that waves in the bar are harmonic so that all the associated mechanical variables can be described by their harmonic components. For instance, the strain tensor $\underline{\underline{\varepsilon}}(z, t)$ can be 
expressed as follows:

$$
\underline{\underline{\varepsilon}}(z, t)=\int_{-\infty}^{+\infty} \underline{\varepsilon}^{*}(\omega) \mathrm{e}^{\mathrm{i}[\tilde{\xi}(\omega) z-\omega t]} \mathrm{d} \omega,
$$

where the upper asterisk denotes frequency components of corresponding temporal functions.

The dispersion relation $\xi=\xi(\omega)$ between the wave number $\xi$ and the frequency $\omega$, describing the propagation of each frequency component, is defined through the so-called frequency equation derived from the solution of the three-dimensional wave propagation in an infinite bar [10].

The signal $\varepsilon_{\mathrm{A}}(t)$ or $\varepsilon_{\mathrm{B}}(t)$ at section $\mathrm{A}$ or B is considered as the component $\varepsilon_{z}$ of the strain tensor $\underline{\underline{\varepsilon}}$ in the axis of the bar (z-axis). For any elementary wave, we have

$$
\begin{aligned}
& \varepsilon_{\mathrm{A}}(t)=\varepsilon_{z}\left(z_{\mathrm{A}}, t\right)=\int_{-\infty}^{+\infty} \varepsilon_{z}^{*}(\omega) \mathrm{e}^{\mathrm{i}\left[\tilde{\xi}(\omega) z_{\mathrm{A}}-\omega t\right]} \mathrm{d} \omega, \\
& \varepsilon_{\mathrm{B}}(t)=\varepsilon_{z}\left(z_{\mathrm{B}}, t\right)=\int_{-\infty}^{+\infty} \varepsilon_{z}^{*}(\omega) \mathrm{e}^{\mathrm{i}\left[\tilde{\xi}(\omega) z_{\mathrm{B}}-\omega t\right]} \mathrm{d} \omega .
\end{aligned}
$$

A separating scheme in the frequency domain can be built. Indeed, the linearity of Eq. (3) shows that the frequency components of the strain can be expressed as the sum of the components of "ascending" and "descending" waves

$$
\begin{aligned}
& \varepsilon_{\mathrm{A}}^{*}(\omega)=\varepsilon_{\mathrm{ascA}}^{*}(\omega)+\varepsilon_{\mathrm{des}}^{*}(\omega), \\
& \varepsilon_{\mathrm{B}}^{*}(\omega)=\varepsilon_{\mathrm{ascB}}^{*}(\omega)+\varepsilon_{\mathrm{des} B}^{*}(\omega) .
\end{aligned}
$$

The wave shifting between $\mathrm{A}$ and $\mathrm{B}$ (separated by the distance $\Delta z=z_{\mathrm{B}}-z_{\mathrm{A}}$ ) consists of multiplying frequency components by a term depending on the dispersive relation

$$
\begin{aligned}
& \varepsilon_{\text {ascB }}^{*}(\omega)=\varepsilon_{\text {ascA }}^{*}(\omega) \mathrm{e}^{\mathrm{i} \xi(\omega) \Delta z}, \\
& \varepsilon_{\text {desB }}^{*}(\omega)=\varepsilon_{\text {desA }}^{*}(\omega) \mathrm{e}^{-\mathrm{i} \xi(\omega) \Delta z} .
\end{aligned}
$$

Using Eq. (7), we can substitute the "descending" wave at A by that at B and also the "ascending" wave at B by that at A so that Eq. (6) leads to

$$
\begin{aligned}
& \varepsilon_{\mathrm{ascA}}^{*}(\omega)=\frac{\varepsilon_{\mathrm{B}}^{*}(\omega)-\varepsilon_{\mathrm{A}}^{*}(\omega) \mathrm{e}^{-\mathrm{i} \xi(\omega) \Delta z}}{\mathrm{e}^{\mathrm{i} \xi(\omega) \Delta z}-\mathrm{e}^{-\mathrm{i} \xi(\omega) \Delta z}}, \\
& \varepsilon_{\mathrm{des}}^{*}(\omega)=\frac{\varepsilon_{\mathrm{A}}^{*}(\omega)-\varepsilon_{\mathrm{B}}^{*}(\omega) \mathrm{e}^{-\mathrm{i} \xi(\omega) \Delta z}}{\mathrm{e}^{\mathrm{i} \dot{\xi}(\omega) \Delta z}-\mathrm{e}^{-\mathrm{i} \xi(\omega) \Delta z}} .
\end{aligned}
$$

Eq. (8) gives the ascendant and descendant waves knowing two strain measurements. However, these equations have multiple singular frequencies. Bacon [30] proposed to use casual condition to solve this problem. Othman et al. [24] and Bussac et al. [25] proposed an interesting integration scheme to realise the FFT inverse in the complex semi-plan to avoid the singular problem for some frequencies in Eq. (8). Using one of these methods, the problem of singular frequencies can be resolved. 
From Eqs. (6)-(8), the force and the velocity in the output side of the specimen are given by

$$
\begin{aligned}
& F_{\text {out }}(\omega)=E_{\mathrm{b}} S_{\mathrm{b}} \frac{\varepsilon_{\mathrm{A}}^{*}(\omega) \sin \left(\xi(\omega) z_{\mathrm{B}}\right)-\varepsilon_{\mathrm{B}}^{*}(\omega) \sin \left(\xi(\omega) z_{\mathrm{A}}\right)}{\sin (\xi(\omega) \Delta z)}, \\
& V_{\text {out }}(\omega)=-\frac{i \omega}{\xi(\omega)} \frac{\varepsilon_{\mathrm{A}}^{*}(\omega) \cos \left(\xi(\omega) z_{\mathrm{B}}\right)-\varepsilon_{\mathrm{B}}^{*}(\omega) \cos \left(\xi(\omega) z_{\mathrm{A}}\right)}{\sin (\xi(\omega) \Delta z)} .
\end{aligned}
$$

The method presented above permits to calculate the velocity and the force in the output side of the specimen. However, in the proposed experimental arrangement (Fig. 9), we lost the measurement of the force and velocity of the input side of specimen, compared with a classical SHPB set-up (Fig. 7). Fortunately, the forces at both side of brass tube is nearly in an equilibrium state because the time for a round trip of wave within the specimen $(104 \mathrm{~mm})$ is small. This assumption is highly interesting. Firstly, we no more need to measure the force at the input side of the specimen. Secondly, knowing this force, the velocity at the input side can be calculated. Indeed, the striker was considered as a bar on which two strain measurements are known (one end is free of stress, another is supposed loaded by the same force as the output one). Hence, the twostrain-separation method discussed above can also be applied to the striker to calculate the velocity.

During the test, the left side of the striker is free. Therefore,

$$
\varepsilon_{\mathrm{A}, \mathrm{s}}^{8}\left(z_{\mathrm{A}, \mathrm{s}}=0, \omega\right)=0 .
$$

Considering that the contact between the striker and the specimen is maintained during the test, the strain at the right side of the striker is given by

$$
\varepsilon_{\mathrm{B}, \mathrm{s}}^{*}\left(z_{\mathrm{B}, \mathrm{s}}=L_{\mathrm{s}}, \omega\right)=F_{\text {out }}(\omega) / E_{\mathrm{s}} S_{\mathrm{s}},
$$

where $L_{\mathrm{s}}, S_{\mathrm{s}}$ and $E_{\mathrm{s}}$ are the length, the section and the Young's modulus of the striker, respectively.

The velocity at the input side of the specimen, $V_{\mathrm{s}}^{\mathrm{mov}}$, is given by the two-separation method. From Eqs. (9)-(11), we have

$$
V_{\mathrm{s}}^{\mathrm{mov}}(\omega)=\frac{i \omega}{\xi(\omega)} \frac{\frac{F_{\text {out }}(\omega)}{E_{\mathrm{s}} S_{\mathrm{s}}} \cos \left(\xi(\omega) L_{\mathrm{s}}\right)}{\sin \left(\xi(\omega) L_{\mathrm{s}}\right)} .
$$

Assuming that the bar and the striker have the same section and the same Young's modulus, from (9) and (12), we obtain

$$
V_{\mathrm{s}}^{\mathrm{mov}}(\omega)=\frac{\mathrm{i} \omega}{\xi(\omega)} \frac{\cos \left(\xi(\omega) L_{\mathrm{s}}\right)\left(\varepsilon_{\mathrm{A}}^{*}(\omega) \sin \left(\xi(\omega) z_{\mathrm{B}}\right)-\varepsilon_{\mathrm{B}}^{*}(\omega) \sin \left(\xi(\omega) z_{\mathrm{A}}\right)\right)}{\sin \left(\xi(\omega) L_{\mathrm{s}}\right) \sin (\xi(\omega) \Delta z)}
$$

The input velocity is then expressed as a function of the two strain measurements recorded on the pressure bar. Eqs. (9) and (13) are integrated in the complex semi-plan (Othman et al., 2001). Let $V_{0}$ be the initial impacting velocity of the striker, which is measured by an optical device, $V_{\mathrm{s}}^{\text {mov }}$ is the expression of the velocity at the input side of the specimen with respect to a reference point moving at a constant velocity $V_{0}$. Therefore, the velocity in the reference of the laboratory is

$$
V_{\text {input }}(t)=V_{0}-V_{\mathrm{s}}^{\mathrm{mov}}(t)
$$




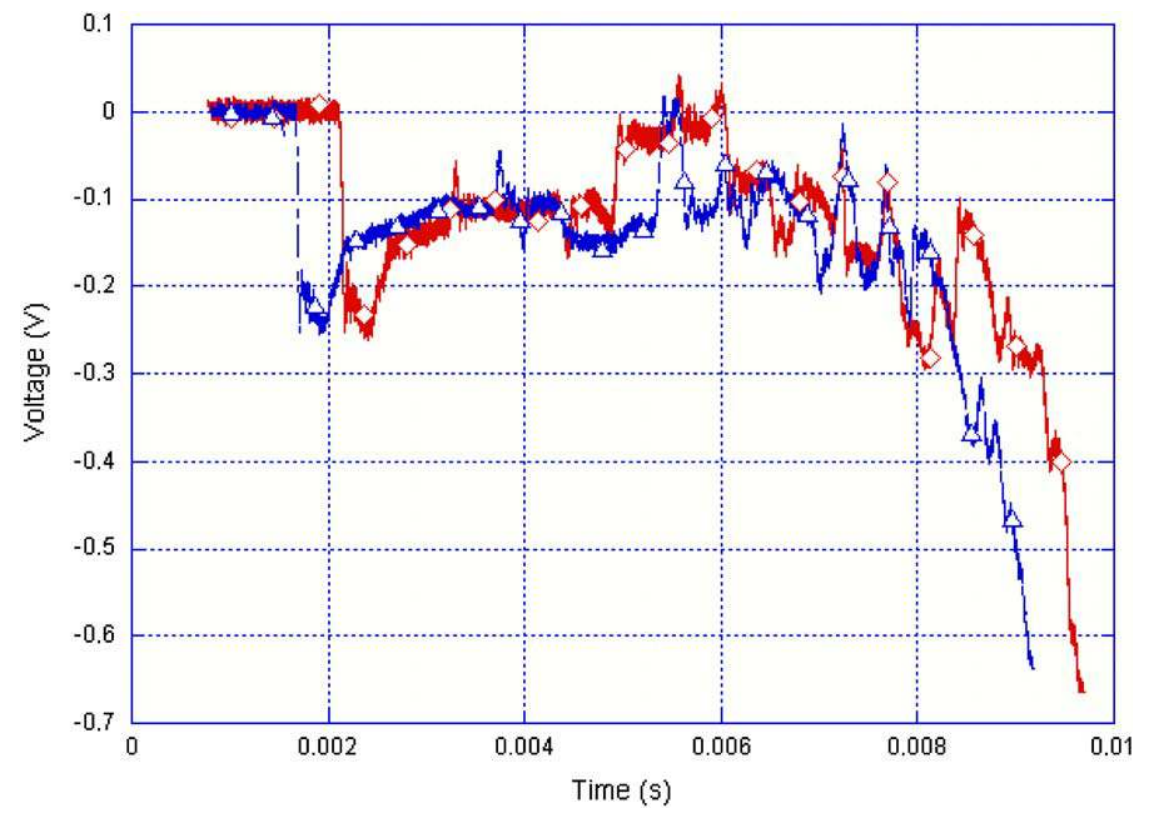

Fig. 10. Typical recordings on brass square tube testing.

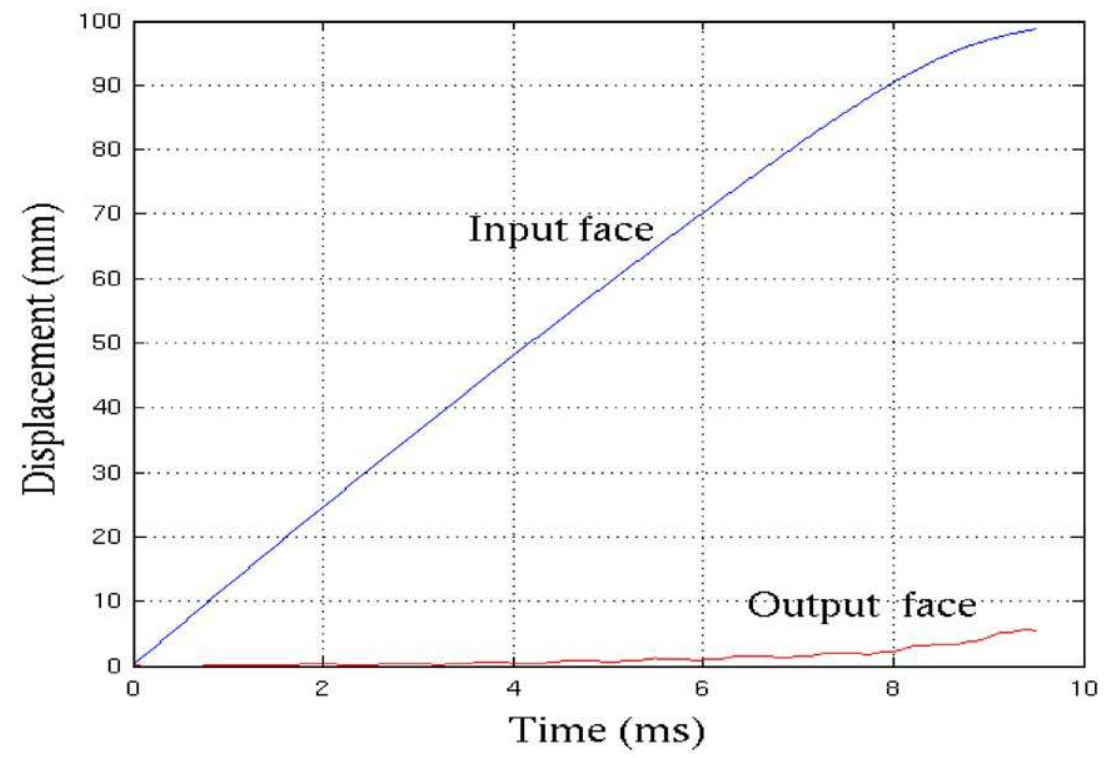

Fig. 11. Displacement measurements at both specimen sides.

\subsection{Typical data processing}

Typical recordings on the two strain gauges are drawn in Fig. 10. From these two basic recordings, we can calculate the two velocities as well as displacements at both sides of tube 

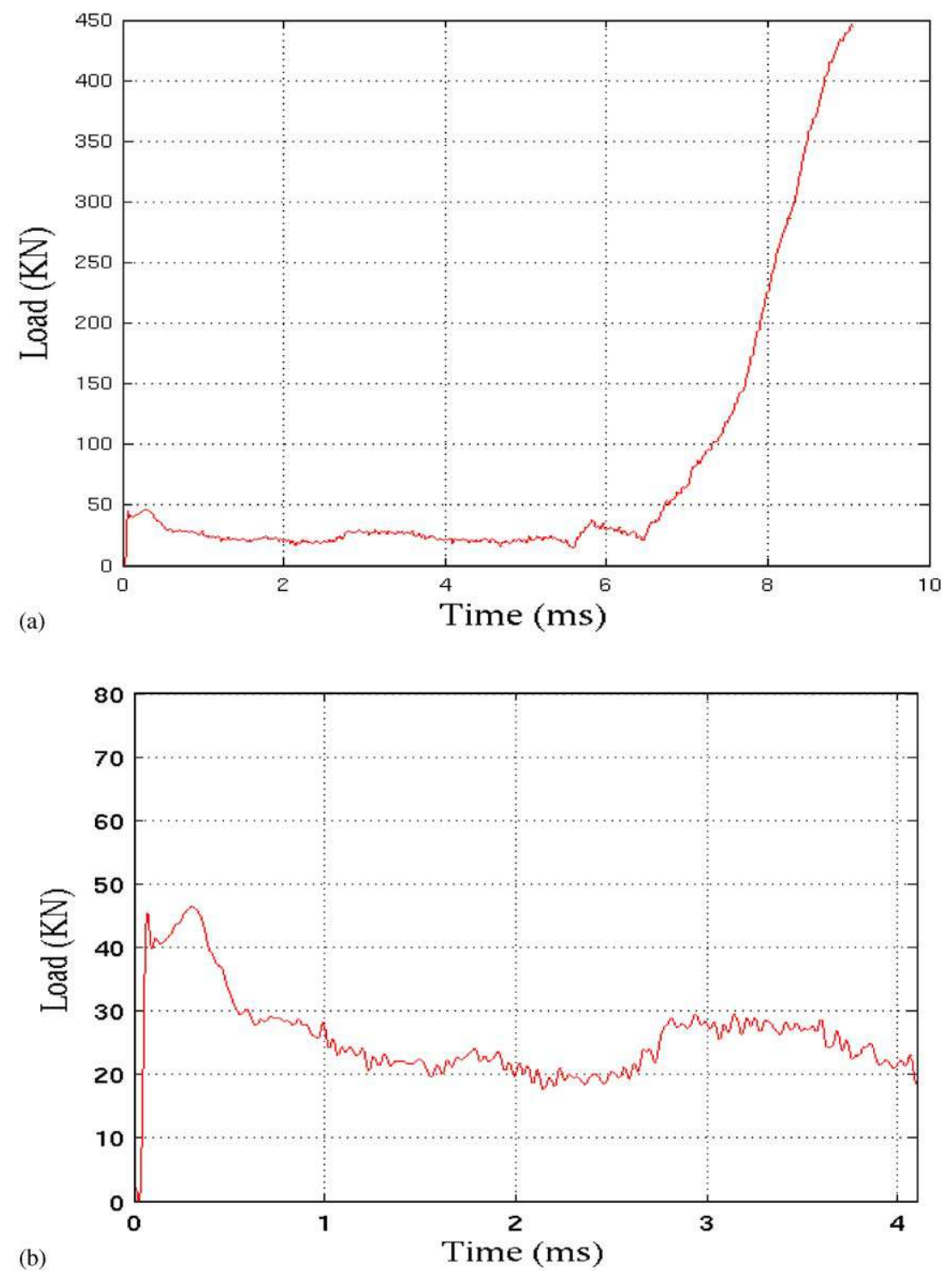

Fig. 12. (a) Force time history at the specimen-bar interface. (b) Detail concerning initial and progressive peak loads.

(Fig. 11). The corresponding calculated force time history is shown in Fig. 12a. A zoom of initial and successive peak load is also drawn in Fig. 12b.

\section{Force increases under impact loading}

In Fig. 13, we compare force-displacement curves under static and dynamic load. Excellent reproducibility is observed under both static and dynamic loading, which indicates the accuracy of 


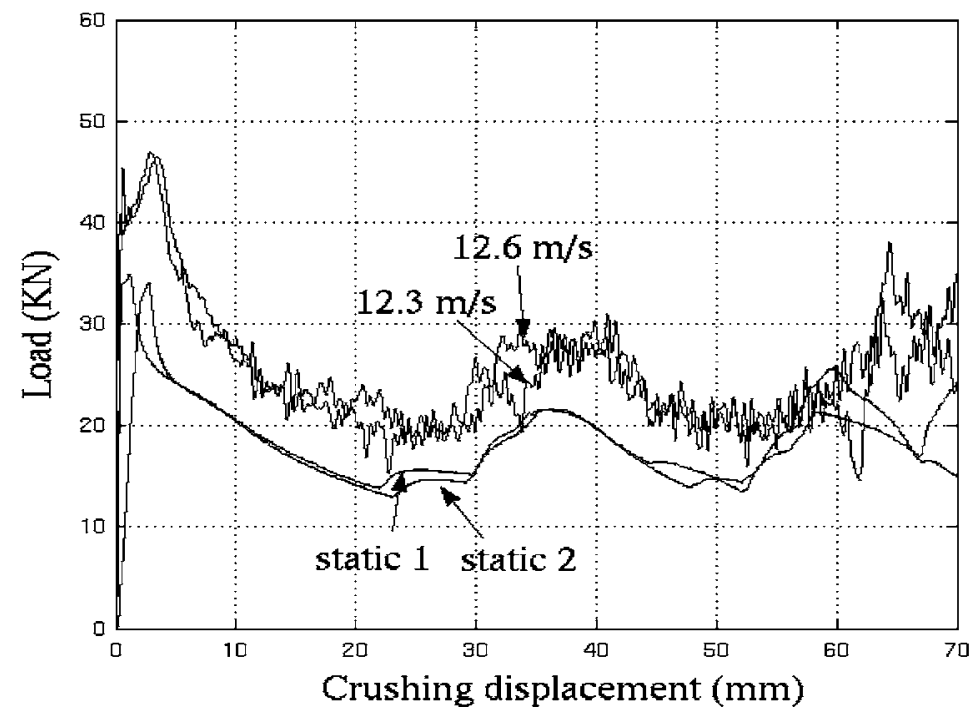

Fig. 13. Force-displacement curves under static and dynamic loading.

Table 1

Statistics of peak loads under impact

\begin{tabular}{llll}
\hline Test & Projectile speed $(\mathrm{m} / \mathrm{s})$ & Initial peak load $(\mathrm{kN})$ & Progressive peak load $(\mathrm{kN})$ \\
\hline 0 & Static & 35 & 22 \\
1 & 7.7 & 43 & 29 \\
2 & 9.6 & 43 & 28 \\
3 & 11 & 45 & 28 \\
4 & 11.5 & 45 & 28 \\
5 & 12.3 & 46 & 29 \\
6 & 12.6 & 47 & 29 \\
7 & 13.5 & 47 & 30 \\
8 & 15.3 & 49 & 31 \\
\hline
\end{tabular}

the whole experimental process. It can be also seen that the crushing displacement of about $40 \mathrm{~mm}$ gives an accurate measurement of the second peak force (successive peak load). The comparison between static and dynamic testing results illustrates a significant enhancement of these successive peak loads which characterise the successive folding process of honeycomb crushing.

Table 1 provides corresponding initial and progressive peak loads under static and different impact loads. It shows clearly that the enhancement exists for the successive peak load. At the impact velocity of $15 \mathrm{~m} / \mathrm{s}$, the successive peak load is increased by $40 \%$ with respect to the static case.

\section{Summary}

This paper presented crushing tests on annealed brass square tube under successive folding mode. Dynamic loading tests are realised with a large scale $(80 \mathrm{~mm}$ diameter and $10 \mathrm{~m}$ length) 
SHPB system. Recently developed two-gauge method is used to obtain a sufficient measuring duration which provides measurement of force-displacement curves of the whole crushing process under impact loading $(7-15 \mathrm{~m} / \mathrm{s})$.

Not only the initial peak load, but also the successive folding peak load are accurately recorded. An enhancement about $40 \%$ of the successive folding peak load is clear and very interesting because successive folding is the main failure mode in the cellular structure such as honeycomb. Meanwhile, careful characterisations of the behaviour of the tube wall material are performed and it proves that there is no notable rate sensitivity till up to $2500 / \mathrm{s}$. This study on the tubes as a model structure suggests that the strength enhancement observed in successive folding of cellular structures can be also caused only by structural inertia effect. A theoretical and numerical study of this inertia effect on the successive folding peak load leads to the same conclusion [31].

\section{Reference}

[1] Wu E, Jiang WS. Axial crush of metallic honeycombs. Int J Impact Eng 1997;19(5-6):439-56.

[2] Reid SR, Peng C. Dynamic uniaxial crushing of wood. Int J Impact Eng 1997;19(5-6):531-70.

[3] Zhao H, Gary G. Crushing behaviour of aluminium honeycombs under impact loading. Int J Impact Eng 1998;21(10):827-36.

[4] Othman R. Extension du champ d'application du système des barres de Hopkinson aux essais à moyennes vitesses de déformation. Thèse de doctorat, Ecole Polytechnique, 2002.

[5] Calladine CR, English RW. Strain-rate and inertia effects in the collapse of two types of energy-absorbing structure. Int J Mech Sci 1984;26(11-12):689-701.

[6] Hild F, Périé JN, Coret M. Mesure de champs de déplacements 2D par intercorrélation d'images. CORRELI2D, LMT-Cachan, Internal Report no. 230, 1999.

[7] Hopkinson B. A method of measuring the pressure in the deformation of high explosives or by the impact of bullets. Philos Trans Roy Soc A 1914;213:437-52.

[8] Kolsky H. An investigation of the mechanical properties of materials at very high rates of loading. Proc Phys Soc B 1949;62:676-700.

[9] Davies RM. A critical study of Hopkinson pressure bar. Philos Trans Roy Soc A 1948;240:375-457.

[10] Zhao H, Gary G. A three dimensional analytical solution of longitudinal wave propagation in an infinite linear viscoelastic cylindrical bar. Application to experimental techniques. J Mech Phys Solids 1995;43(8):1335-48.

[11] Zhao H, Gary G. On the use of SHPB techniques to determine the dynamic behaviour of materials in the range of small strains. Int J Solids Struct 1996;33(23):3363-75.

[12] Lindholm US. Some experiments with the split Hopkinson pressure bar. J Mech Phys Solids 1964;12:317-35.

[13] Abramowicz W, Jones N. Dynamic axial crushing of square tubes. Int J Impact Eng 1984;2(2):179-208.

[14] Abramowicz W, Jones N. Dynamic progressive buckling of circular and square tubes. Int J Impact Eng 1986;4(4):243-70.

[15] Langseth M, Hopperstad OS. Static and dynamic axial crushing of square thin-walled aluminium extrusions. Int J Impact Eng 1996;18(7-8):949-68.

[16] Harrigan JJ, Reid SR, Reddy TY. Accurate measurement of impact force pulses in deforming structural component. In: Allison, editor. Experimental Mechanics. Rotterdam: Balkema; 1998.

[17] Hauser FE. Techniques for measuring stress-strain relations at high strain rates. Exp Mech 1966;6:395-402.

[18] Campbell JD, Duby J. The yield behaviour of mild steel in dynamic compression. Proc Roy Soc London A $1956 ; 236: 24-40$.

[19] Lundberg B, Henchoz A. Analysis of elastic waves from two-point strain measurement. Exp Mech 1977;17:213-8.

[20] Zhao H, Gary G. A new method for the separation of waves. Application to the SHPB technique for an unlimited measuring duration. J Mech Phys Solids 1997;45:1185-202. 
[21] Meng H, Li QM. A SHPB set-up with reduced time-shift and pressure bar length. Int J Impact Eng 2003;28:677-96.

[22] Park SW, Zhou M. Separation of elastic waves in split Hopkinson bars using one-point strain measurement. Exp Mech 1999;39:287-94.

[23] Casem DT, Fourney W, Chang P. Wave separation in viscoelastic pressure bars using single-point measurements of strain and velocity. Polym Testing 2003;22:155-64.

[24] Othman R, Bussac MN, Collet P, Gary G. Séparation et reconstruction des ondes dans les barres élastiques et viscoélastiques à partir de mesures redondantes. CR Acad Sci IIb 2001;329:369-76.

[25] Bussac MN, Collet P, Gary G, Othman R. An optimisation method for separating and rebuilding one-dimensional dispersive waves from multi-point measurements. Application to elastic or viscoelastic bars. J Mech Phys Solids 2002;50:321-49.

[26] Jaquelin E, Hamelin P. Force recovered from three recorded strains. Int J Solids Struct 2003;40:73-88.

[27] Pochhammer L. Uber die fortpflanzungsgeschwindigkeiten kleiner schwingungen in einem unbergrenzten isotropen kreiszylinder. J. Reine Angew Math 1876;81:324-36.

[28] Chree C. The equations of an isotropic elastic solid in polar and cylindrical co-ords, their solutions and applications. Cambridge Philos Soc Trans 1889;14:250-369.

[29] Lifshitz JM, Leber H. Data processing in the split Hopkinson pressure bar tests. Int J Impact Eng 1994;15:723-33.

[30] Bacon C. Separation of waves propagating in an elastic or viscoelastic Hopkinson pressure bar with threedimensional effects. Int J Impact Eng 1999;22:55-69.

[31] Zhao H, Abdennadher S. On the strength enhancement under impact loading of square tubes made from rate insensitive metals. Int J Solids Struct 2004;41:6677-97. 